Shilun Zhao

Chaohe Chen

Tianhui Fan*

Yong Jiang

Yijun Shen

http://dx.doi.org/10.21278/brod70102

ISSN 0007-215X

eISSN 1845-5859

\title{
FATIGUE ASSESSMENT OF CRACK GROWTH BASED ON FAILURE ASSESSMENT DIAGRAMS FOR A SEMI-SUBMERSIBLE PLATFORM
}

UDC 629.563.21:629.5.015.4

Original scientific paper

\begin{abstract}
Summary
This paper deals with the assessment of fatigue crack propagation on the connection between column and brace for a semi-submersible. The analysis of global and local structural responses under different sea states are performed to acquire the transfer functions of stresses. Based on an existing crack the Failure Assessment Diagrams (FAD) are applied as criterion of acceptance for the safety of crack and structure during the crack growth calculation cycle. The crack growth rate considering threshold stress intensity factor and stress ratio is used. During safety assessment the stress response from ultimate sea state is outlined. A comparison of fatigue crack growth using ultimate stress and normal stress data with different crack growth rate is presented. The results show the reliability of fatigue assessment using FAD as a measurement of acceptability of crack propagation.
\end{abstract}

Key words: $\quad$ Crack propagation; Semi-submersible; FAD; Fracture mechanics; Structural safety; Offshore platform

\section{Introduction}

Currently the S-N curve is still effective in engineering field for the fatigue life estimation subjected to the initial state of crack failure. For ship structure that is exposed to fatigue damage reliability-based method [1] is also used in the inspection planning or other aspects corresponding to marine structures. Even aging effects on marine structure integrity [2] are also considered in recent study. In general, the fatigue life is deemed on the occurrence of crack or other types of severe structural defect. Fracture mechanics is introduced in the fatigue assessment and becoming more popular in the aspect of crack propagation which is specifically acknowledged as the second stage of the entire fatigue process. Due to the complexity of the interaction between aggressive marine environment and fatigue wave load, methods for fatigue crack assessment varies from many situations. Nevertheless, all the practices are based on Paris Law [3] and Palmgren-Miner's rule of cumulative damage ratio. Throughout recent years several types of crack growth rate have been developed for the crack growth calculation. McEvily [4] and his co-workers developed the modified constitutive 
relation which considered the initial defect and effects of load sequence. Huang and Moan [5][6][7] presented the unique crack growth rate model which determined the material constants for fatigue life prediction of structures subjected to various amplitude loading history. Cui [8] applied this unique crack growth model into the crack growth calculation for several key parts of a deep water semi-submersible.

As a long-term interaction between offshore structure and marine environment fatigue assessment depends on various factors such as wave loading history, corrosion, wind and other environmental attacks. A basic safety requirement during the crack growth process should not be ignored and thus the Failure Assessment Diagrams (FAD) [9] is introduced in each load cycle during the cracking process. In the field of subsea pipeline, the FAD have been a useful tool for assessing the acceptability of flawed pipelines and also in the fatigue assessment for tubular joints [11] even for non-metallic materials safety assessment [12]. However only constant amplitude loading is used in the normal FAD process and irregular random wave loads are dominant in fatigue assessment. This paper provides a method for using irregular wave load with FAD and performs fatigue assessment of an existing crack. After the global and local structural response analysis, the crack growth calculation will consider the ultimate stress for safety assessment in FAD process. To use random loads, the fatigue wave load history is applied by combining the stress transfer function and wave scatter diagram. It is necessary to split the fatigue wave load into separate cycle for creating single load case for every step of crack growth. Then a comparison is presented for discussion of using ultimate stress response and stress generated by wave loading history in the crack growth calculation. The results show the feasibility and reliability of the method in fatigue crack growth calculation and assessment.

\section{Analysis Approach}

\subsection{Separate Fatigue load cycles}

For better understanding a comparison of S-N curve and FAD is listed below in Table 1.

Table 1 Methods Comparison of S-N Curve and FAD

\begin{tabular}{|c|c|c|}
\hline Description & S-N curve & FAD \\
\hline Considering crack growth & No & Yes \\
\hline Stage of fatigue development & Until occurrence of crack & Until failure of crack \\
\hline Criterion of structure failure & Crack(s) found & FAD outreached \\
\hline Fatigue load & Long term load distribution & Regular constant amplitude load \\
\hline Considering sequence of loads & No & No \\
\hline Considering stress components & No & Yes \\
\hline Using crack growth rate & No & Yes \\
\hline Crack safety evaluation & No & Yes \\
\hline Considering random wave load & Yes & No \\
\hline
\end{tabular}

From Table 1 the advantages of introducing FAD into offshore structure fatigue assessment are clearly demonstrated. The only problem is implementing irregular wave load into Separate assessment cycle. According to BS 7910 for the situation of using variable amplitude loading, the stress spectrum should be represented as a distribution of stress ranges versus numbers of occurrences [9]. Based on the P-M rules of linear damage accumulation, the wave scatter diagram can be introduced for dividing the consecutive long-term load distribution into Separate cycles. In this paper wave scatter diagrams in respect to 8 
directional sea states are provided by CNOOC Energy Technology \& Services Limited. A diagram of North direction to the semisubmersible is listed below in Table 2.

Table 2 Wave Scatter Data in North Direction (\%)

\begin{tabular}{|c|c|c|c|c|c|c|c|c|}
\hline$H_{s}(\mathrm{~m})$ & \multicolumn{7}{|c|}{$T_{z}(\mathrm{~m})$} & Total \\
\hline & $<2$ & $2 \sim 3$ & $3 \sim 4$ & $4 \sim 6$ & $6 \sim 8$ & $8 \sim 10$ & $>10$ & \\
\hline 0 & - & - & 0 & 0 & 0 & - & - & 0 \\
\hline $0 \sim 0.5$ & - & - & 0.05 & 0.17 & 0.01 & - & - & 0.22 \\
\hline $0.5 \sim 1$ & - & - & 0 & 0.57 & 0.05 & 0 & - & 0.61 \\
\hline $1 \sim 1.5$ & - & - & - & 0.19 & 0.04 & 0.01 & - & 0.23 \\
\hline $1.5 \sim 2$ & - & - & - & 0.03 & 0.11 & 0.02 & - & 0.16 \\
\hline $2 \sim 2.5$ & - & - & - & 0.01 & 0.1 & 0.01 & - & 0.12 \\
\hline $2.5 \sim 3$ & - & - & - & - & 0.23 & 0.05 & 0 & 0.28 \\
\hline $3 \sim 3.5$ & - & - & - & - & 0.01 & 0.11 & 0.01 & 0.14 \\
\hline $3.5 \sim 4$ & - & - & - & - & 0.01 & 0.03 & 0 & 0.04 \\
\hline $4 \sim 4.5$ & - & - & - & - & 0 & 0 & - & 0 \\
\hline $4.5 \sim 5$ & - & - & - & - & - & - & - & 0 \\
\hline$>5$ & - & - & - & - & - & - & - & - \\
\hline Total & 0 & 0 & 0.05 & 0.96 & 0.56 & 0.23 & 0.01 & 1.8 \\
\hline
\end{tabular}

In Table $2 H_{s}$ and $T_{z}$ are presenting significant wave height and average cross zero period respectively. For a specific significant wave height $H_{i}$ the fatigue stress range $\Delta \sigma_{\bar{i}}$ can be described as

$$
\Delta \sigma_{i}=H_{i} \times \Delta \sigma_{\text {wnit }}
$$

where $\Delta \sigma_{\text {unit }}$ is stress range under unit wave height by picking maximum stress $\sigma_{m x}$ and minimum stress $\sigma_{m n}$ from stress transfer functions at different phase positions under the same period.

Supposed the annual cycle number of $\Delta \sigma_{i}$ under $H_{i}$ is $n_{y i}$ then

$$
n_{y i}=365 \times 24 \times 3600 \times \frac{p_{i}}{T_{z i}}
$$

where $T_{z i}$ is the cross zero period of $H_{i}$ and $p_{i}$ is the probabilistic occurrence rate of $H_{i}$ and $T_{z i}$.

Based on above separation process of irregular wave loads the fatigue assessment of crack growth can be represented as a series of $\Delta \sigma_{\bar{i}}$ versus $n_{y i}$. This is a method for assessing the acceptability of crack growth in each fatigue cycle using FAD under irregular amplitude wave load. The complete fatigue assessment procedure is illustrated in Figure 1. 


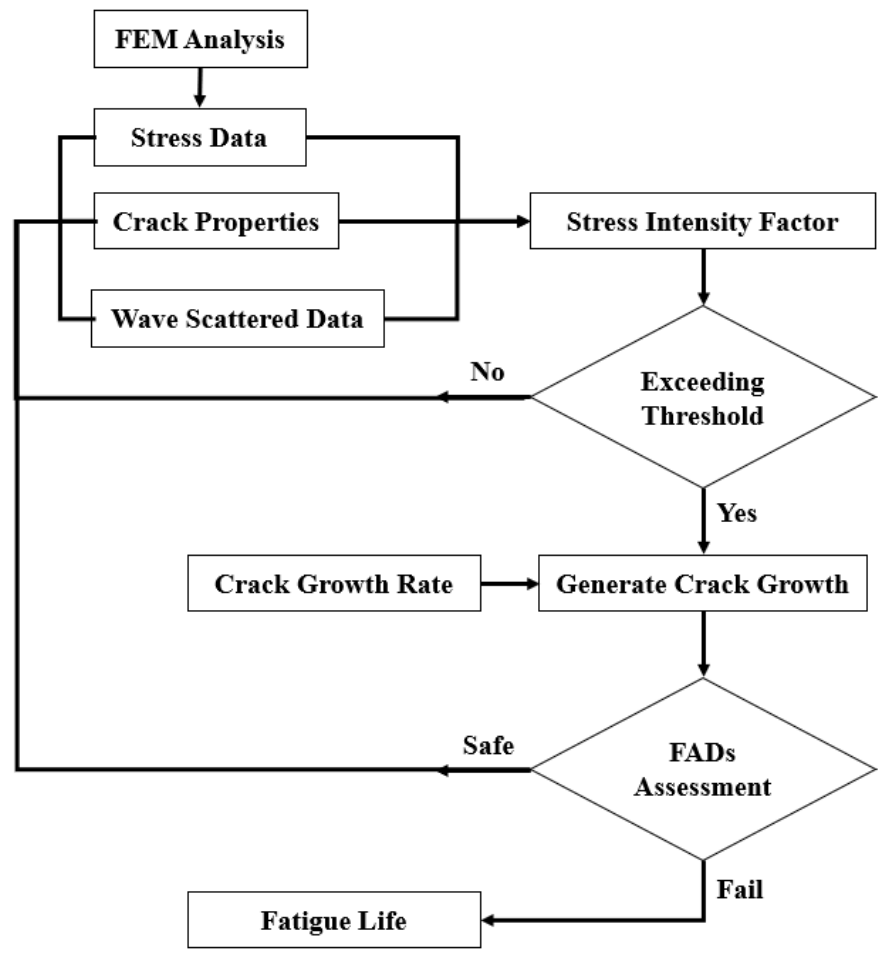

Fig.1 Fatigue Assessment Flowchart

Crack growth cycle starts from the $1^{\text {st }}$ wave direction which is followed by picking up the periods. Under the specific period all the wave heights in the wave scatter data will be applied with the stress range in the calculation of SIF. The crack growth cycle number under a specific $\Delta \sigma_{i}$ aligns with $n_{y i}$. Namely the propagation process proceeds with different $n_{y i}$ under corresponding $\Delta \sigma_{i}$. A new crack growth generation under a new $\Delta \sigma_{i+1}$ starts with the end of previous number of $n_{y i}$. A year is counted when all the wave directions and periods are used in the crack propagation process.

The overall procedure relies on FEM analysis of the semisubmersible. The structural stress responses are obtained from the FEM analysis under various sea states. The stress transfer functions are extracted from previous step under unit wave amplitude. For the weld geometry of the cracked component, the hot spot stress $\sigma_{h s}$ is calculated via extrapolation from stresses $\sigma_{0.5 t}$ and $\sigma_{1.5 t}$ at readout points $0.5 \mathrm{t}$ and $1.5 \mathrm{t}$ [12],

$$
\sigma_{h s}=0.5 \times\left(3 \cdot \sigma_{0.5 t}-\sigma_{1.5 t}\right)
$$

When the stress ranges are all prepared then stress intensity factor (SIF) $K_{I}$ can be calculated for the fatigue assessment with other parameters determined by the weld profile and the crack, such as initial crack size in depth $a_{0}$, crack size in width $c_{0}$, angle $\theta$ from $c_{0}$ to $a_{0}$, etc. The fatigue assessment processes with the crack growth rate under a single load cycle to obtain an increment $\Delta a$ on the crack growth size up to the critical crack size $a_{\varepsilon}$. Before generating a new crack size $a_{i}=a_{i-1}+\Delta a$ the FAD is used to analyze the acceptability of the $a_{i}$. For conservatism the stress responses under potential critical wave load used in the FAD assessment to evaluate the crack growth status while the wave scatter data is used in calculating the crack propagation increments. This procedure continues until the assessment point of $a_{i}$ outreaches the assessment line which presents the acceptable limit. At this stage the crack is deemed as failure and the fatigue life of the welded structure is set due. The 
sequence of 8 diagrams applied in crack growth cycles is in clockwise from North to North West. A reversed sequence of diagrams is also performed in the crack growth process using Paris law for comparison. Since it is based on the Palmgren-Miner's rule of a linear crack growth accumulation, the effect of loading sequence of stress range within each diagram is ignored.

\subsection{Failure Assessment Diagrams (FAD)}

These diagrams are one of the main engineering tools for assessing the fracture-plastic collapse in the cracked components. Simultaneously the fracture and plastic collapse are assessed by normalized parameters fracture ratio $K_{r}$ and load ratio $L_{r}$ defined as following,

$$
\begin{aligned}
& K_{r}={ }^{K} / K_{\text {mat }} \\
& L_{r}=\sigma_{r e f} / \sigma_{Y}
\end{aligned}
$$

The fracture ratio of $K_{I}$ to $K_{\text {mat }}$, corresponding to stress intensity factor and material fracture toughness respectively, evaluates the current cracked component against fracture. The load ratio of $\sigma_{r e f}$ to $\sigma_{Y}$, representing the reference stress and yield strength, is to evaluate the component against plastic collapse. The reference stress $\sigma_{\text {ref }}$ varies from different types of crack. Nevertheless, it is defined by primary membrane and bending stress components $P_{m} P_{b}$, also by crack depth $a$, crack width $c$, plate thickness $B$ and width in plane of flaw $W$. For the case of surface flaw under normal bending strain considered in this paper, $\sigma_{r e f}$ is defined as following,

$$
\sigma_{r e f}=\frac{P_{b}+\left[P_{b}{ }^{2}+9 P_{m}{ }^{2}\left(1-\alpha^{m}\right)^{2}\right]^{0.5}}{3\left(1-\alpha^{m}\right)^{2}}
$$

where

$$
\begin{aligned}
& \alpha^{n}=\frac{2 a / B}{1+(B / c)} \text { for } W \geq 2(c+B) \\
& \alpha^{n}=(a / B)(2 c / W) \text { for } W<2(c+B)
\end{aligned}
$$

Corresponding to various types of crack which is denoted as flaw in the BS 7910:2013 [9], the specifications of $\sigma_{\text {ref }}$ can be referred in Annex M and P of the document.

Generally, the failure assessment line is defined as following,

$$
K_{r}=f\left(L_{r}\right)
$$

It will be modified due to different situations such as requirement of stress-strain data or ductile tearing. According to BS 7910 Option 1 approach is selected because of lacking uniaxial tensile stress-strain data and not considering ductile crack growth. For these two situations Option 2 and Option 3 approaches are introduced in BS 7910. The assessment line of Option 1 is defined as below,

$$
\begin{cases}f\left(L_{r}\right)=\left(1+0.5 L_{r}^{2}\right)^{-0.5}\left[0.3+0.7 \exp \left(-\mu L_{r}^{6}\right)\right] & \text { for } L_{r} \leq 1 \\ f\left(L_{r}\right)=f(1) \cdot L_{r}^{(N-1) /(2 N)} & \text { for } 1<L_{r} \leq L_{r, \max } \\ f\left(L_{r}\right)=0 & \text { for } L_{r}>L_{r, \max }\end{cases}
$$


where $\mu, N$ are defined as

$$
\begin{aligned}
& \mu=\min \left(0.001 \frac{E}{\sigma_{Y}}, 0.6\right) \\
& N=0.3\left(1-\frac{\sigma_{Y}}{\sigma_{I I}}\right)
\end{aligned}
$$

In the equation $\sigma_{U}$ represents tensile strength of material and $E$ is elastic modulus.

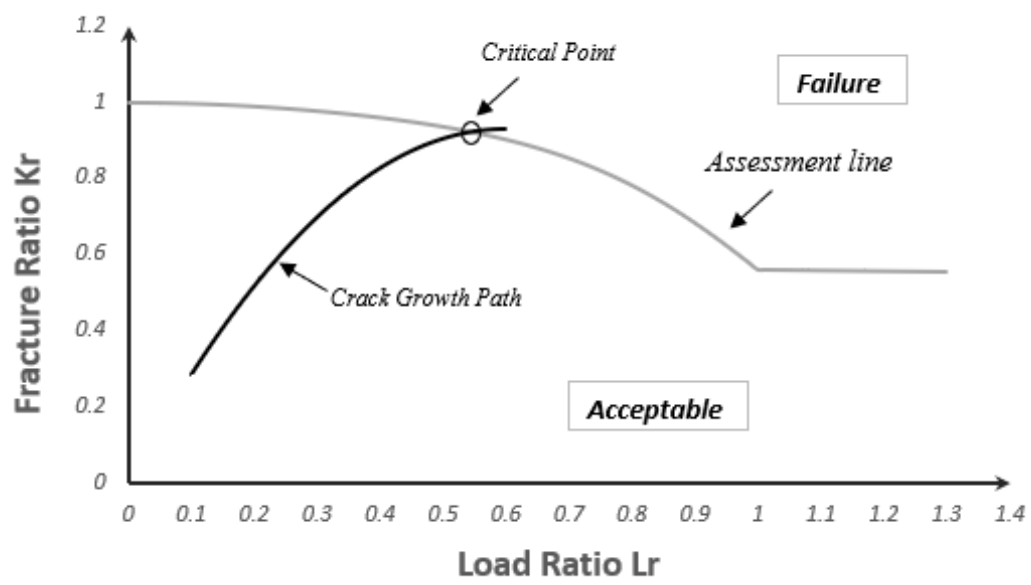

Fig.2 Option 1 Assessment Line

Figure 2 illustrates the Option 1 assessment line and path of assessment points on the same coordinate and their relationships on defining the critical point of failure. The crack growth path is not the real time growing direction of the crack on welded joint but a set of the assessment points. $L_{r, \max }$ is the permitted value of $L_{r}$ and is set at a point as

$$
L_{r, m a x}=\frac{\sigma_{Y}+\sigma_{U}}{2 \sigma_{Y}}
$$

The purpose of $L_{r_{2} \max }$ is to prevent plastic collapse and assessment line is cut off where the $L_{r, \max }$ is reached.

\subsection{Fatigue Crack Growth Law}

Paris law is the typical crack growth rate expression from experimental practice. Considering a threshold value of $\Delta K_{0}$, the stress intensity factor corresponding to the hot spot stress range of cracked component, $d a / d N$ is assumed to be zero if the value of $\Delta K$ is below the value of $\Delta K_{0}$. Based on Paris law a modified $d a / d N$ is used in the calculation of crack propagation.

$$
\begin{aligned}
& \frac{d a}{d N}=C\left[\left(\Delta K_{E}\right)^{m}-\left(\Delta K_{t h 0}\right)^{m}\right] \\
& \Delta K_{E}=M_{R} \Delta K \\
& M_{R}=\left\{\begin{array}{l}
(1-R)^{-\beta_{1}} \\
(1-R)^{-\beta} \\
\left(1.05-1.4 R+0.6 R^{2}\right)^{-\beta}
\end{array}\right.
\end{aligned}
$$


This is the unique crack growth rate developed by Huang [5] for the fatigue life prediction of marine steel structures. Since crack growth rates of welded joint under different applied loading ratios behaves independently, the purpose of bringing up this modified crack growth rate is to establish a concise model for crack growth data under different stress ratios $R$ to the curve corresponding to $R=0 . \Delta K_{E}$ and $\Delta K_{\text {tho }}$ are stress intensity factor and threshold value on the level of $R=0 . M_{R}$ is the modifying factor for stress ratio $R$. According to Huang [5,6,7], most of the crack growth rate data gathers around the curve on the level of $R=0$ after transferring the $d a / d N-\Delta K$ data into $d a / d N-\Delta K_{E}$ data.

In equation $\beta$ and $\beta_{1}$ are parameters depending on material property and environment. Material constants $C, m$ are these corresponding to $R=0$. For offshore structures Huang [5] recommends

$$
\begin{aligned}
& \beta=0.22+\frac{0.65}{1+0.0035 \Delta K^{4}} \\
& \beta_{1}=0.84
\end{aligned}
$$

Huang [5] also recommends the mean value crack growth rate under insufficient data for material if the unique crack growth rate is applied

$$
\frac{d a}{d N}=8.32 \times 10^{-9}\left(\Delta K_{E}^{2.88}-7.2^{2.88}\right)
$$

Besides Huang's recommendation the crack growth rate based on Paris law

$$
\frac{d a}{d N}=C(\Delta K)^{m}
$$

is assumed to be a reference compared to the mean value crack growth rate. Constants $C, m$ that depend on material and the applied conditions differ in two situations. Both values of $C$ and $m$ for Paris law are defined in BS 7910:2013 [9].

For the simplified fatigue crack growth rate $C=2.3 \times 10^{-12}$ and $m=3$ under the marine environment at temperatures up to $20^{\circ} \mathrm{C}$, with or without cathodic protection, both values above are recommended for steels (excluding austenitic stainless steels). Due to situation of overtaken design fatigue life and the cathodic protection has lost effect, the fatigue crack growth threshold for welded joint is set to $\Delta K_{0}=0 \mathrm{~N} / \mathrm{mm}^{3 / 2}$.

\subsection{Stress Intensity Factor for Fatigue Assessment}

The stress intensity factor $\Delta K$ is determined by following equation

$$
\Delta K=Y(\Delta \sigma) \sqrt{\pi a}
$$

where $Y$ is the stress intensity correction factor. It contains the primary stress and secondary stress components specifically defined in BS 7910:2013 and for the fatigue assessment only primary stress components offer contribution on the crack growth. Nevertheless, for the fracture assessment both stress components are necessarily considered [9]. 
Shilun Zhao, Chaohe Chen

Tianhui Fan, Yong Jiang, Yijun Shen
Fatigue Assessment of Crack Growth Based on Failure Assessment Diagrams for Semi-Submersible

\section{Analysis Approach}

\subsection{Finite Element Modelling (FEM)}

The finite element model of the semi-submersible is established via ANSYS suite, as seen in Figure 3. The principle dimensions of semisubmersible are given in Table 3. Basically, two level of finite element (FE) models are used in the fatigue assessment [13]. Level one consists of the semi-submersible global FE model and is used to obtain global stress and strain on the connection of aft column and brace, where the crack is discovered. In level two the connection is modeled with internal vertical and horizontal stiffeners at each plate and frame. As seen in Figure 4 a refined mesh with boundary condition defined is created on the interconnected plates between brace and outer shell of column.

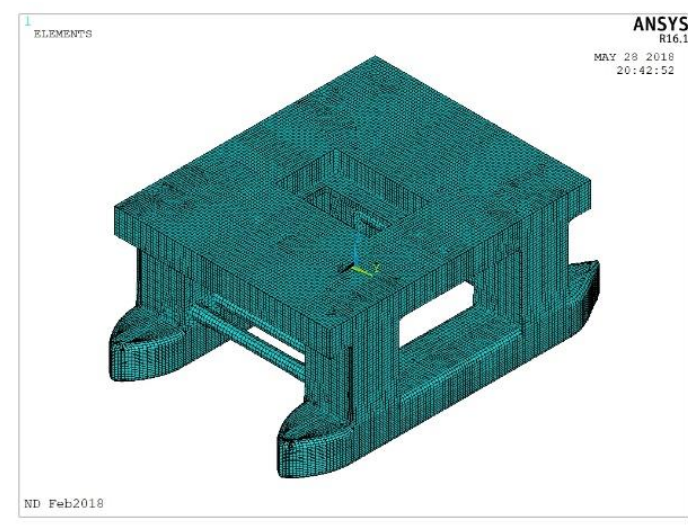

Fig.3 Finite Element Model

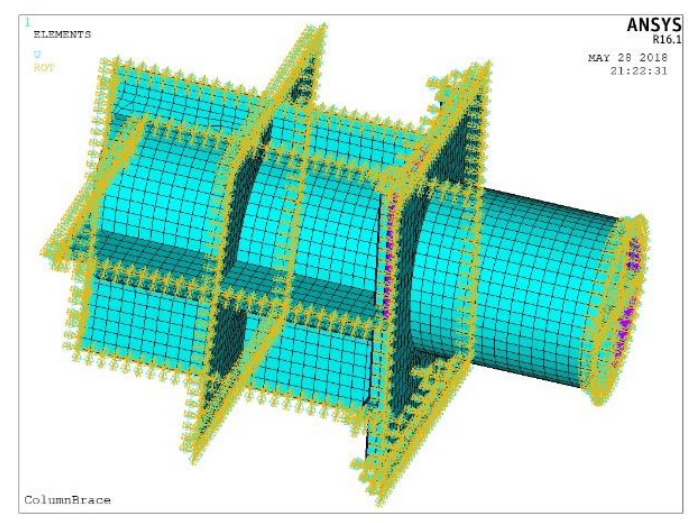

Fig.4 Local Structure Model

The elements used in the FEM analysis are BEAM188, SHELL181 and MASS21 regarding to line body, surface body and mass unit respectively. The local connection is modeled by slicing the edges from global structure and the boundary conditions are obtained by interpolating the nodes on the cutting edges. According to previous study relating to crack propagation solid elements are applied in the finite element analysis on crack tip positioning and crack grow path predicting [14][15][16]. However, the stress response is the only focused parameter in the crack propagation process with built in FAD assessment. Hence the crack tip opening position and the crack grow path are not considered in the element simulation. Considering the integrity and accuracy of load transfer, SHELL 181 is used in the global structure as well as local connection and the mesh is refined for adjacent are around the initial crack.

For the global FE model mesh size is defined in accordance with the spacing of frames. The mesh size of element for connection FE model is set to $1 \sim 1.5 \mathrm{t}$, where $t$ is the plate thickness. Boundary conditions are defined at the main deck plane by constraining 3 different nodes according to DNV GL rules [17].

Table 3 Principle Dimensions of Semisubmersible

\begin{tabular}{|c|c|c|c|c|c|}
\hline Length & Width & Depth & \multicolumn{2}{|c|}{ Displacement } & Water Depth \\
\hline $104.5 \mathrm{~m}$ & $71.5 \mathrm{~m}$ & $42.0 \mathrm{~m}$ & \multicolumn{2}{|c|}{$44060 \mathrm{ton}$} & $1500 \mathrm{~m}$ \\
\hline \multirow{2}{*}{ Wetted Area } & \multirow{2}{*}{ Draft } & \multicolumn{2}{|c|}{ Moment of Inertia $\left(\mathrm{x} 10^{10} \mathrm{~kg}^{*} \mathrm{~m}^{2}\right)$} \\
\cline { 3 - 6 } & & Ixx & Iyy & Izz \\
\hline \multicolumn{2}{|c|}{$11933 \mathrm{~m}^{2}$} & $21 \mathrm{~m}$ & 4.450 & 5.465 & 7.767 \\
\hline
\end{tabular}


8 different sea states headings aligned with 8 directional wave scatter diagrams are considered during the hydrodynamic pressure analysis from $0^{\circ}$ to $360^{\circ}$ with interval of $45^{\circ}$ and 18 periods from 3s to 30s with interval of 1.5s. According to DNV GL codes [18] each load case corresponding to one period and one wave heading should be calculated at two-time instances, namely corresponding to a wave crest amidships and a wave zero crossing at the same point. Thus, two phase positions of $0^{\circ}$ and $270^{\circ}$ are applied in each period and a total number of load case is $8 \times 18 \times 2=288$ while the number of stress range is $8 \times 18=144$. These pressures applied on the subsea part of structure under different sea state are transferred by AQWA WAVE as Figure 5 shows. During the FE analysis of global structure several characteristic hydrodynamic responses are considered for potential strength failure, such as split force between pontoons $F_{s}$, torsion moment about a transverse horizontal axis $M_{t}$, longitudinal shear force between the pontoons $F_{L}$, longitudinal acceleration of deck mass $a_{L}$, transverse acceleration of deck mass $a_{T}$, vertical acceleration of deck mass $a_{V}$. Definitions for these kinds of responses are given in DNV GL codes [18] and these types of responses correlate to various potential critical load cases of the structure. A design wave approach [18] is applied for the semi-submersible platform to define design wave loads and to evaluate the stress of characteristic responses. In table 4 the periods and wave heights of corresponding response are listed and the first principle stress of local joint (Node No. 39700) where the crack is located are also listed in the last column. Crest position describes positions of the wave zero-crossing point and the wave crest regarding to midship of semi-submersible platform. Boundary conditions of local connection are obtained via global FE model strain responses. Figure 6 shows Von Mises equivalent stress distribution of local connection under ultimate sea state of $45^{\circ}$ and ultimate stress $\sigma_{\text {ult }}=47 \mathrm{MPa}$ is obtained. It is derived from load case of $F_{L}$ with period $=8.98 \mathrm{~s}$ and wave height $=17.9 \mathrm{~m}$ and the wave zero-crossing amidships.

Table 4 Stress under Characteristic Response

\begin{tabular}{|c|c|c|c|c|c|c|}
\hline Load Case & $\begin{array}{c}\text { Characteristic } \\
\text { Response } \\
\end{array}$ & $\begin{array}{c}\text { Period } \\
(\mathrm{s})\end{array}$ & $\begin{array}{c}\text { Direction } \\
\text { (degree) }\end{array}$ & $\begin{array}{c}\text { Wave Height } \\
(\mathrm{m})\end{array}$ & $\begin{array}{c}\text { Crest Position } \\
(\text { degree })\end{array}$ & $\begin{array}{l}1^{\text {st }} \text { Principle } \\
\text { Stress }(\mathrm{MPa})\end{array}$ \\
\hline 01 & \multirow{2}{*}{$F_{s}$} & \multirow{2}{*}{8.98} & \multirow{2}{*}{90} & \multirow{2}{*}{14.528} & 0 & 21.62 \\
\hline 02 & & & & & 270 & 18.84 \\
\hline 03 & \multirow{2}{*}{$M_{t}$} & \multirow{2}{*}{7.85} & \multirow{2}{*}{120} & \multirow{2}{*}{10.486} & 0 & 16.46 \\
\hline 04 & & & & & 270 & 22.04 \\
\hline 05 & \multirow[b]{2}{*}{$F_{L}$} & \multirow{2}{*}{8.98} & \multirow{2}{*}{45} & \multirow{2}{*}{17.916} & 0 & 46.85 \\
\hline 06 & & & & & 270 & 20.22 \\
\hline 07 & \multirow[b]{2}{*}{$a_{L}$} & \multirow{2}{*}{6.98} & \multirow{2}{*}{0} & \multirow{2}{*}{12.014} & 0 & 20.31 \\
\hline 08 & & & & & 270 & 14.65 \\
\hline 09 & \multirow[b]{2}{*}{$a_{T}$} & \multirow{2}{*}{6.28} & \multirow{2}{*}{90} & \multirow{2}{*}{11.352} & 0 & 19.68 \\
\hline 10 & & & & & 270 & 29.07 \\
\hline 11 & \multirow[b]{2}{*}{$a_{V}$} & \multirow{2}{*}{10.47} & \multirow{2}{*}{0} & \multirow{2}{*}{22.476} & 0 & 31.24 \\
\hline 12 & & & & & 270 & 24.76 \\
\hline 13 & \multirow{2}{*}{$F_{L}+F_{s}$} & \multirow{2}{*}{8.98} & \multirow{2}{*}{60} & \multirow{2}{*}{17.342} & 0 & 32.03 \\
\hline 14 & & & & & 270 & 20.14 \\
\hline 15 & \multirow[b]{2}{*}{$M_{t}+F_{s}$} & \multirow{2}{*}{7.85} & \multirow{2}{*}{120} & \multirow{2}{*}{11.683} & 0 & 16.52 \\
\hline 16 & & & & & 270 & 22.03 \\
\hline
\end{tabular}




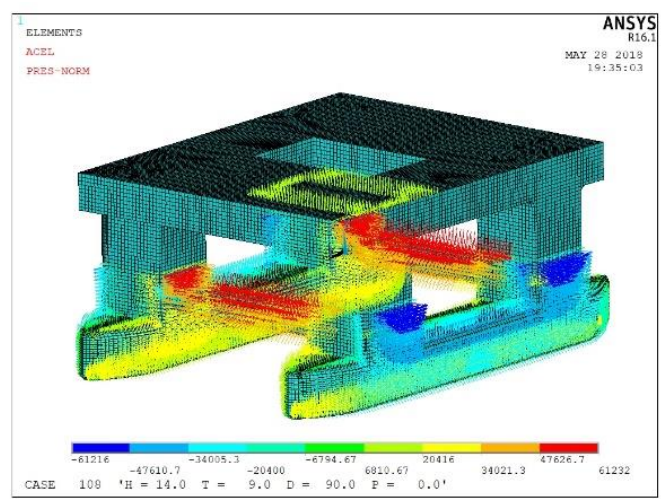

Fig.5 Hydrodynamic Pressures

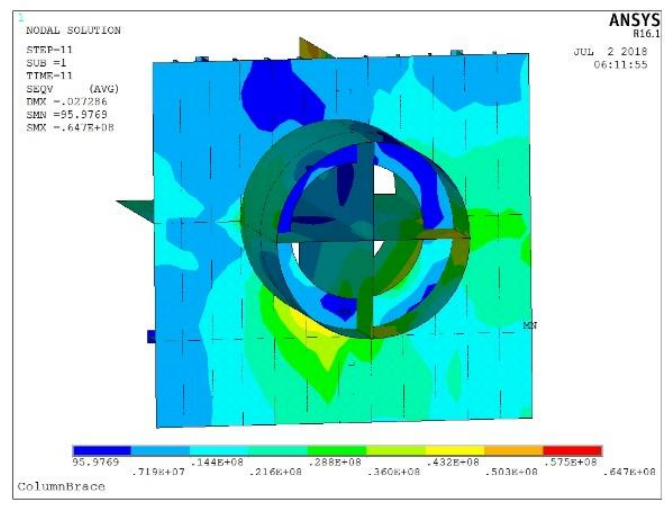

Fig.6 Local Connection Stress

\subsection{Define Crack Properties}

As crack growth process is very sensitive to input parameters, the initial crack dimensions are carefully selected in previous study. For example, N S. Ermolaeva [20] decides the depth and width of crack according to BS 7910:2005 for analyzing partial penetration weld in a steeling casting. Other studies [8][13][20][21] also choose the initial dimensions of crack based on current codes in a conservative way when they are lacking available data of crack properties. It is also recommended to use actual crack data detected by available devices [9] as Wolfgang Fricke [22] and G. Terán [23] perform physical fatigue test on welded steel structures.

The type of material used is DH36 and the yield strength $\sigma_{Y}$ and tensile strength $\sigma_{U}$ are $355 \mathrm{MPa}$ and $490 \mathrm{MPa}$ respectively. Crack located in the plate between left aft column and brace is detected upon subsea inspection by ACFM device and is parallel to the direction of weld, considered as toe crack for conservatism. According to the definition of flaw types from BS 7910:2013, this crack is defined as surface planar flaw due to its orientation and location in the connection. The initial crack depth $a_{0}=1.5 \mathrm{~mm}$, initial crack width $c_{0}=2.3 \mathrm{~mm}$. The adjacent plate thickness of aft column is $t=40 \mathrm{~mm}$.

\subsection{Fatigue Assessment Results and Discussions}

Crack growth calculation proceeds after the FEM analysis by splitting fatigue load distribution into Separate cycles as described in chapter 2.1. Using 2 types of crack growth rate and using stress range under ultimate sea state as unique constant fatigue load for the propagation calculation, also using the Paris Law under the reversed load sequence of wave scatter diagrams. the results are listed below in Table 3. The paths of assessment points under 2 types of growth rate are recorded in Figure 7 . The crack growth in depth $a$ with the increment of load cycles is presented in Figure 8.

From Table 5 the results from four different calculations are compared. The critical crack size including depth and width are similar. The deviations between all the critical crack sizes are less than $9 \%$. The biggest deviation is between $a_{f 1}$ and $a_{f 2}$, which is $8.24 \%$. The largest depth value obtained under Paris law while the largest width value acquired under ultimate sea state with Paris law. The shortest remaining life happened under ultimate sea state with Paris law which only gives a result of 1 year and the longest can be seen under Paris law giving 14 years. 
Table 5 Fatigue Assessment Results

\begin{tabular}{|c|c|c|c|c|}
\hline \multirow[b]{2}{*}{ Crack Parameters } & \multicolumn{4}{|c|}{ Local Connection } \\
\hline & $\begin{array}{c}\text { 1. Paris Law } \\
\text { (ultimate sea state) }\end{array}$ & 2. Paris Law & $\begin{array}{l}\text { 3. Reversed } \\
\text { Sequence }\end{array}$ & $\begin{array}{l}\text { 4. Unique Crack } \\
\text { Growth Rate }\end{array}$ \\
\hline Initial Fracture Ratio $K_{r 0}$ & 0.3427 & 0.3427 & 0.3427 & 0.3427 \\
\hline Initial Load Ratio $L_{r 0}$ & 0.2797 & 0.2797 & 0.2797 & 0.2797 \\
\hline Critical Fracture Ratio $K_{r f}$ & 0.9677 & 0.9604 & 0.9738 & 0.9738 \\
\hline Critical Load Ratio $L_{r f}$ & 0.4079 & 0.4199 & 0.4249 & 0.4249 \\
\hline Critical Crack Depth $a_{f}$ & $13.94 \mathrm{~mm}$ & $15.09 \mathrm{~mm}$ & $15.05 \mathrm{~mm}$ & $14.83 \mathrm{~mm}$ \\
\hline Critical Crack Width $c_{f}$ & $24.01 \mathrm{~mm}$ & $23.35 \mathrm{~mm}$ & $23.29 \mathrm{~mm}$ & $23.06 \mathrm{~mm}$ \\
\hline Number of Cycles & 10346 & 74625 & 74636 & 57503 \\
\hline Remaining Life of Crack & 1 year & 14 years & 14 years & 10 years \\
\hline
\end{tabular}

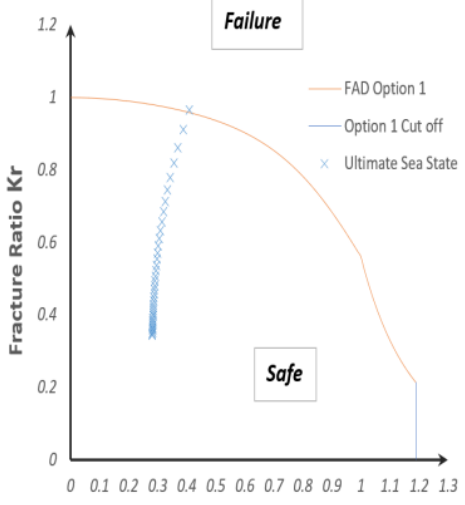

Load Ratio Lr

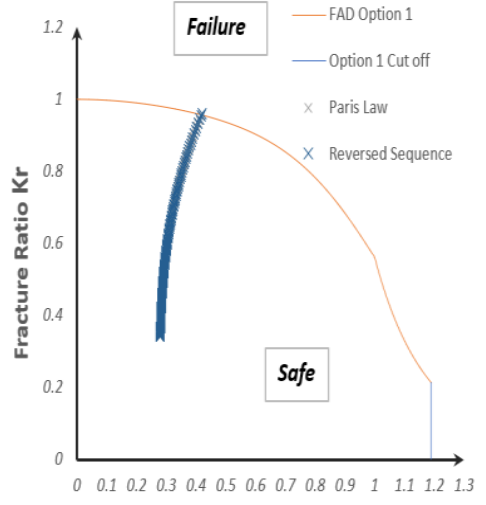

Load Ratio Lr

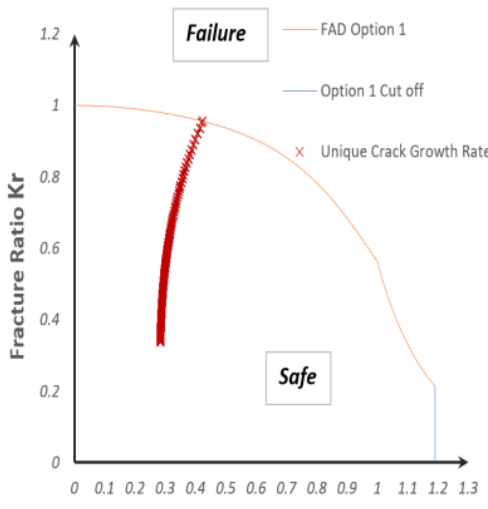

(b)

(c)

Fig.7 Paths of Assessment Points

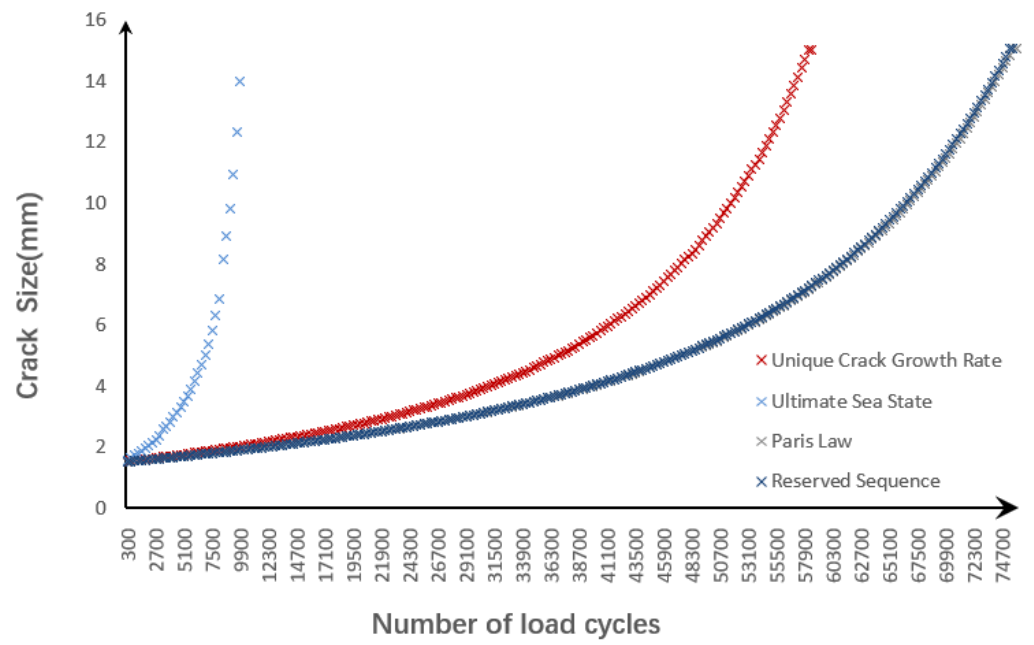

Fig.8 Crack Size versus Numbers of Load Cycle 
This fact can be explained by the stress range used within the crack growth cycles. Ultimate stress range contributes more in each fatigue cycle with bigger values of $\Delta K$ than the stress ranges from wave scatter diagram do. This is also reflected from Figure 7 that the numbers of assessment points are less from Figure 7 (a) than from Figure 7 (b)\&(c). The numbers of assessment points represent the effective load cycles from different load case. Thus, with bigger value of $\Delta K$ within a crack growth cycle the crack growth size on depth $a_{i}$ or width $c_{i}$ is bigger, which means fatigue crack propagates faster. The structure will reach failure with less fatigue load cycles. This can contribute to shorter remaining life.

According to Table 5 and Figure 7, using unique crack growth rate to calculate and assess fatigue crack gives results on an intermediate level other than those using Paris law under ultimate sea state and pure Paris law. It shows in Figure 8 that the crack growth process generates less 17000 load cycles approximately under unique crack growth rate than under Paris law. In terms of critical crack sizes, they are relatively close when it comes to two crack growth rates with $1.7 \%$. and $1.3 \%$ deviation in depth and width respectively. This is aligned with the theory study of Huang [5,6,7] and practice of Cui [8]. Huang pointed that mean value unique crack growth rate was obtained by transferring crack growth rate under any stress ratio to that under zero stress ratio. Comparing to the database of curves of $d a / d N$ versus $\Delta K$ the curve under zero stress ratio is in the mediate level among the curves under other values of stress ratio (from $R=0.05 \sim 0.8$ ). Cui performed fatigue crack growth with consecutive stress spectrum using Huang's unique crack growth rate and obtained shorter remaining fatigue life than using traditional Paris law. This fact is also approved in this paper by using splitting consecutive stress ranges into separate fatigue load cycle and adding in the FAD as a standard for evaluating the safety and acceptability of each fatigue crack growth in the load cycles.

By comparing the results from crack propagation under normal sequence and reversed sequence, as shown in Table 5, Figure 7(b) and Figure 8, it can be concluded that random loading sequence from wave scatter diagrams merely has an effect in the separate crack growth cycles. As it is mentioned above this separate propagation process is based on linear damage accumulation, for a specific diagram the range of $H_{s}$ and $T_{z}$ with the combination of load cases are set. Thus, the results from 2 type of sequences are almost equal and the effect of loading sequence of diagrams can be ignored.

Furthermore, the largest critical crack size (in depth or in width), $a_{f}=15.09 \mathrm{~mm}$ and $c_{f}=24.01 \mathrm{~mm}$, is still far from penetrating the plate thickness, $t=40 \mathrm{~mm}$, of the local connection between column and brace. Above all, it proves that the method applied in this paper can provide a reasonable and reliable result on calculating and assessing structural fatigue crack.

According to the Shao [10], who performed physical tests on the crack in a T shape tubular joint and applied FAD on assessing the safety of welded tubular joint containing fatigue cracks, all types of failure assessment diagrams have sufficient safety redundancy and using FAD in assessing welded tubular joints is safe and relatively conservative. Thus, it can be concluded that using Option 1 assessment line is safe on assessing fatigue crack growth. Besides, based on above works the results obtained in this paper could be reliable preference for engineering practice. 


\section{Conclusions}

In this paper a new method for calculating and assessing fatigue crack growth in column and brace connection of semisubmersible is introduced. By splitting consecutive stress spectrum or stress ranges into the distribution of stress ranges versus their occurrences using scatter diagram, the Option 1 assessment line is added into the separate crack growth cycles as a tool for assessing the propagation safety of fatigue crack. Using unique crack growth rate on predicting critical crack size and remaining life is more reliable than using traditional Paris law. Option 1 assessment line is optional on choosing FAD according to previous study since all kinds of current FAD are relatively conservative.

This method is based on P-M rules of linear accumulative damage, which is widely acknowledged suitable in engineering practices. By comparing crack growth process under normal and reversed sequences of loading using wave scatter diagrams, it is approved that the effect of loading sequence of diagrams can be ignored. Through the assessment of FAD it can be assured that each crack growth size $a_{i}$ or $c_{i}$ is considered as acceptable in fatigue load cycles. Due to lack of physical tests data the accuracy of the calculation is still under investigation. However, by comparing to existent study the practice in this paper still provides reasonable results on the critical values of fatigue crack and is proved to be aligned with previous work. The method presented in this paper extends the use of FAD to the randomly loaded offshore structure by applying wave scatter diagrams and separating crack growth cycles. According to Table 1 it considers the stress components which include the primary and secondary stress components in the stress intensity factor and via applying wave scatter diagrams and by splitting crack growth process into separate cycles, the accuracy of crack propagation calculation is improved and more reliable with the safety evaluation of FAD. Therefore, it is concluded the method presented in this paper is practical in fatigue assessment of semisubmersible and reliable on providing critical values of fatigue crack.

\section{Acknowledgment}

This paper was financially supported by National Natural Science Foundation of China (Grant No. 51709118); China Postdoctoral Science Foundation (Grant No. 2017M612669); Science and Technology Program of Guangzhou (Grant No. 201804010482); the Fundamental Research Funds for the Central Universities (Grant No.2017BQ089); the Funds for Marine Economic Development of Guangdong, China (Grant no. GDME-2018B003); by State Key Laboratory of Ocean Engineering (Shanghai Jiao Tong University)(Grant No. 1708); and by State Key Laboratory of Coastal and Offshore Engineering (Dalian University of Technology)( Grant No. LP1805).

\section{REFERENCES}

[1] Zareei, Mohammad Reza; Iranmanesh, Mehdi. Reliability-based inspection planning of the ship structure exposed to fatigue damages[J]. BRODOGRADNJA, Vol: 69, Issue: 2, p119-134, JUN 2018.

[2] Jurisic, Paul; Parunov, Josko; Garbatov, Yordan. Aging effects on ship structural integrity[J]. BRODOGRADNJA, Vol: 68, Issue: 2, p15-28, JUN 2017.

[3] Paris P C, Erdogan F. A critical analysis of crack propagation laws[J]. Journal of Basic Engineering, 1963, 85(4): 528 -534. https://doi.org/10.1115/1.3656900

[4] McEvily A J, EiFler D, MaCherauch E. Ananalysis of the growth of short fatigue cracks[J]. Engineering Fracture Mechanics, 1991, 40(3): 571-584. https://doi.org/10.1016/0013-7944(91)90151-P

[5] Huang X P, Moan T, Cui W C. A unique crack growth rate curve method for fatigue life prediction of steel structures[J]. Ships and Offshore Structures, 2009, 4(2): 165-173. https://doi.org/10.1080/17445300902732370 
[6] Huang X P, Moan T, Cui W C. An engineering model of fatigue crack growth under variable amplitude loading[J]. International Journal of Fatigue, 2008, 30(1): 2-10.

https://doi.org/10.1016/j.ijfatigue.2007.03.004

[7] Huang X P, Moan T. Improved modeling of the effect of R-ratio on crack growth rate[J]. International Journal of Fatigue, 2007, 29(4): 591-602. https://doi.org/10.1016/j.ijfatigue.2006.07.014

[8] CUI Lei, HE Yong, MAO Jiang-hong, JIN Wei-liang. Crack propagation-based fatigue life analysis for deep water semi-submersible platform[A]. Journal of Ship Mechanics, 2013, 17(11): 1318-1327.

[9] BS 7910, Guide to methods for assessing the acceptability of flaws in metallic structures[S]. London: British Standards, 2013.

[10] SHAO Yong-bo, SONG Sheng-zhi, LI Tao. Study on safety of circular tubular t-joints containing fatigue crack based on failure assessment diagram(FAD)[J]. Gongcheng Lixue/Engineering Mechanics, 2013 Vol.30 No.9, p184-193.

[11] Fuentes J.D. On the use of British standard 7910 option 1 failure assessment diagram to non-metallic materials[J] Fatigue and Fracture of Engineering Materials and Structures, v41, n1, p146-158, 2018.

[12] DNVGL-RP-0005: Fatigue design of offshore steel structures [S]. Norway: Det Norske Veritas, 2014-06.

[13] Sudhakar Tallavajhula, Jim Wang, Inge Solberg. Strength and Fatigue Analysis of Vim Suppression Strakes for Large Diameter Spars[C]. Proceedings of the 26th International Conference on Offshore Mechanics and Arctic Engineering 2007. OMAE2007-29078. https://doi.org/10.1115/OMAE2007-29078

[14] Mir Ali Ghaffari, Hossein Hosseini Toudeshky. Fatigue Crack Propagation Analysis of Repaired Pipes with Composite Patch Under Cyclic Pressure[J]. Journal of Pressure Vessel Technology, Vol. 135 / 031402-1, 2013.

[15] T. Okawaa, Y. Sumia, M. Mohri. Simulation-based fatigue crack management of ship structural details applied to longitudinal and transverse connections[J]. Marine Structures, 19 (2006) 217-240, 2007.

[16] Haitao Wu, Guoqiang Zhou, Zemin Wu, Jiancheng Leng. Simulation of Crack Propagation on The Weld Line of Offshore Platform Leg[J]. Oil Field Equipment, 2015, 44(8): 6-10.

[17] DNVGL-RP-C103: Fatigue design of offshore steel structures[S]. Norway: Det Norske Veritas, 2015-07.

[18] DNVGL-OS-C103: Structural design of column stabilized units - LRFD method[S]. DNV, 2015-07.

[19] N S. Ermolaeva, T. Ward, W. Bateman, V. Parsoya. Fracture mechanics in fatigue calculations as the assistance in structural design. Case study[J]. Engineering Failure Analysis, 35 (2013) 652-664, 2013.

[20] Wentao He, Jingxi Liu, De Xie. Numerical study on fatigue crack growth at a web-stiffener of ship structural details by an objected-oriented approach in conjunction with ABAQUS[J]. Marine Structures, 35 (2014) 45-69, 2014.

[21] R. Jones, B. Chen, S. Pitt. Similitude: Fatigue cracking in steels[J]. Theoretical and Applied Fracture Mechanics, 48 (2007) 161-168. https://doi.org/10.1016/j.tafmec.2007.05.007

[22] Wolfgang Fricke, Nils Friedrich, Luciano Musumeci, Hans Paetzold. Low-cycle fatigue analysis of a web frame corner in ship structures[J]. Welding in the World, 2014, 58 (3) :319-327. https://doi.org/10.1007/s40194-014-0117-z

[23] G. Terán, R.C. Meléndez, A. Albiter, C. Maldonado, A.Q. Bracarense. Characterization of the mechanical properties and structural integrity of T-welded connections repaired by grinding and wet welding[J]. Materials Science \& Engineering A 599 (2014) 105-115. https://doi.org/10.1016/j.msea.2014.01.078

[24] Vasudeven A K, Sadananda K, Louat N.A review of crack closure, fatigue crack threshold and related phenomena[J]. Materials Science and Engineering, 1994, 188(1-2): 1-22. https://doi.org/10.1016/09215093(94)90351-4

[25] Sadananda K, Vasudevan A K. Short crack growth and internal stresses[J]. International Journal of Fatigue, 1997, 19(93):99-108. https://doi.org/10.1016/S0142-1123(97)00057-1

[26] Fuentes J.D. On the use of British standard 7910 option 1 failure assessment diagram to non-metallic materials[J] Fatigue and Fracture of Engineering Materials and Structures, v41, n1, p146-158, 2018.

Submitted: 21.07.2018. Shilun Zhao, Chaohe Chen, Tianhui Fan, fanth@ scut.edu.cn School of Civil Engineering and Transportation, South China University of Accepted: 28.11.2018. Technology Jiaotong Building 402B, South China University of Technology, Guangzhou, Guangdong 510640, China 